\title{
Critical Aspects of Project Management Causing Major Impacts on Software Development
}

\author{
M. Aqeel lqbal \\ Dept. of SE, Foundation \\ University, Institute of \\ Engineering and \\ Management Sciences, \\ Rawalpindi, Pakistan
}

\author{
Farooque Azam \\ Dept. of CE, College of \\ Electrical \& Mechanical Eng, \\ National University of \\ Sciences and Technology \\ (NUST), Islamabad, Pakistan
}

\author{
Ahmed Ali Qureshi \\ Dept. of SE, Foundation \\ University, Institute of \\ Engineering and \\ Management Sciences, \\ Rawalpindi, Pakistan
}

\begin{abstract}
The development process for modern softwares has become a solid engineering paradigm rather than a social activity. In this regard the project management for software development has become one of the most leading areas of interest. An affective project management and development methodology can lead to successful high quality software. The effectiveness of software project management is dependent on multi-disciplinary, interrelated factors including the management of project scope, project time, project cost, project quality, project human resource, project communication, project procurement and project integration. In this research paper a critical review has been presented about the modern practices being under used for software project management. The paper point outs the different critical aspects of the software project management causing high impacts on software development and on the society itself. A large number of co-related project management aspects with their impacts have been critically analyzed for further active research work for exposing new methodologies for managing the project activities.
\end{abstract}

\section{Keywords}

Software Project Management, Critical Aspects of Project Management, Roles of Project Manager, Project Management and Software Development

\section{INTRODUCTION}

Historical perspective of the projects shows that the projects development is not new to humans. The concerned people have ever been working on different projects since the very early days of organized activities or joint work [1]. The very much famous the Egyptian Pyramids, the Greek Parthenon and the Great Chinese Wall are considered to be the examples of mega projects of great historic importance. The only new happening is the new procedures and tolls being used for the development and management of the projects. Typical project management philosophy and methodologies have evolved as a special kind of management work from the modern engineering work that has been done on very large-scale military related projects [2]. In such kind of projects an organized approach and a set of properly managed activities was considered to be the necessary work to manage the very complex dependencies or interrelationships among a large number of related different tasks being performed by a group of different specialized persons. Consider the Figure-1 in which it has been clarified that what kinds of activities are performed during the action of project management. In general these activities may include Project Initiation, Project Planning, Project Execution, Project Monitoring and Control and Project Closure etc. Figure-1 Source: http://www2.swc.toshiba.co.jp

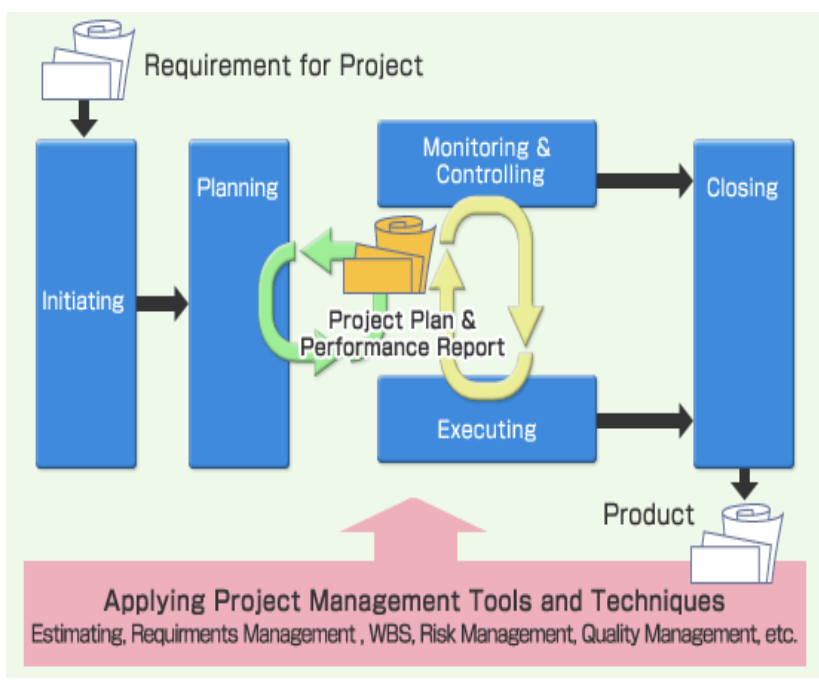

Figure-1: Project Management Activities

Recently the field of project management has risen as an emerging shape of critical management based skill to critically tackle with the internally involved matters of knowledge based team-work in large scale organizations which have been facing the most rapidly varying business policies and running environments. The field of project management in fact provides the powerful techniques and emerging tools for project planning, project organizing and managing the project team-based activities for accomplishing specific objectives [3]. Consider the Figure-2 which shows the different activities being run in the life of project management. Broadly it includes the detailed objectives being achieved during the project definition, project planning, project tracking and project close-up etc.

As far as the role of project management for the development of the softwares is concerned, none of other management activities can take benefit more than software development from effective project management [4]. In reality almost all kinds of software development works are carried out as typical projects of certain level of complexity. A far as the nature of the software 
development projects is concerned, it has been observed that such kind of projects generally appear to be very complex and their underlying development is carried out in a more versatile environment.

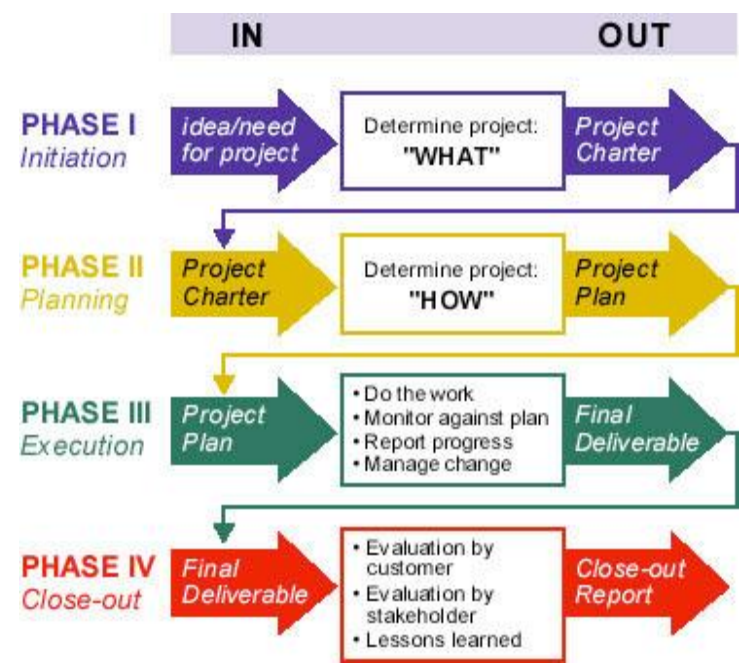

Figure-2: Sequence of Project Management Activities

Commonly it has been observed that the software development environment has dynamic nature where business constraints and the under hand technologies vary during the projects life cycles [5]. Mostly it has been observed that the users of the projects are mostly quite unsure of their needs and due to this reason they may frequently change their requirements just in the midway of the projects. This is the one of the major causes that the software development industry is normally plagued by factors like cost overruns, late deliveries, very poor reliability and commonly user dissatisfaction.

In the current era of science and technology, the emerging needs of the society in terms of computing resources and systems have grown to much higher level than ever before [6]. The project management in most of areas of development is becoming one of the most challenging tasks for project development organizations. This is so because of the reason of that, the success factor of most projects is based on multi-dimensional aspects and becomes one of the most critical goals for project development organizations.

\section{FUNDAMENTAL PILLERS OF PROJECTS}

According to the modern analysis being done in the field of project management it has been justified that any project is critically dependant on three fundamental pillars or legs.

1. Development Cost

2. Implementation Schedule

3. Working Performance

In order to make a project to be a successful project it is necessary that, these project pillars must be perfectly balanced, completely planned in advance and properly managed throughout the development life cycle of the project. It has been observed that the more rigorous deployment of proper project management techniques used as principle concepts on the development of any project greatly improves the balancing of the three pillars of the project and hence leads to the path of project success. Proper project management in principle involves the different aspects including the project planning, project organizing, project staffing, project directing and control [7]. These factors have been a major cause for the failure of multi-dimensional as well as commonly developed commercial projects. Consider the Figure- 3 which shows the basic elements of the management. These components generally include planning, staffing, controlling, organizing and directing.

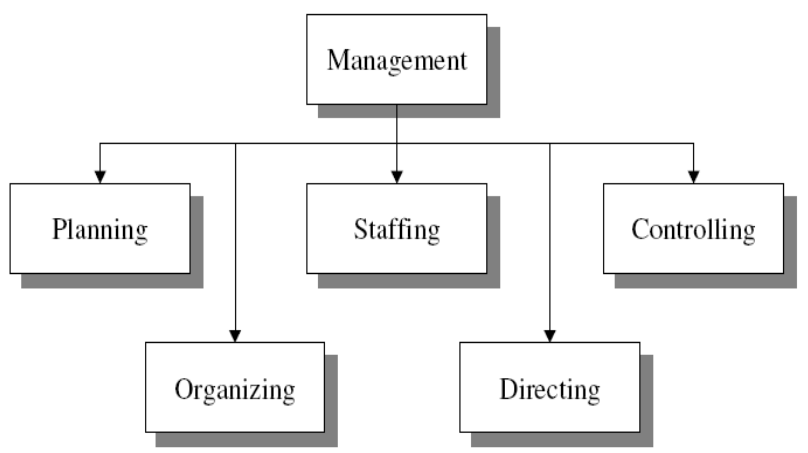

Figure-3: Components of Management

\subsection{Project Organization}

It involves the establishment of a basic structure that should be filled up by the concerned persons and is basically aimed to reach up the pre-defined basic objectives of the project. It also defines the basic job contents, logical interfaces, work responsibilities, regulating authority and the process of resource allocation.

\subsection{Project Staffing}

It involves the filling of the job posts being available in the firm's structure being defined with the most suitable people. It also involves the keeping of the positions of organization filled positively, in order to successfully run the project plan. Consider the Figure-4 for project staffing concept in an organization.

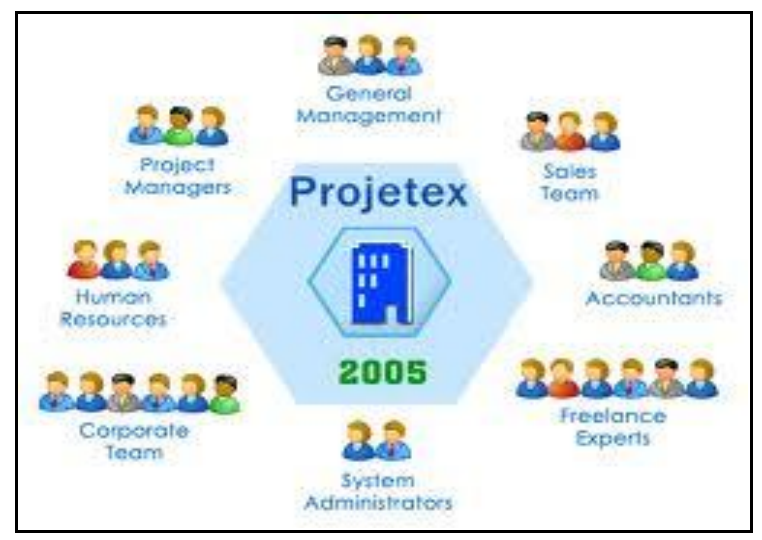

Figure-4: Project Staffing Details 


\subsection{Project Directing}

It involves the creating of a suitable environment in which the concerned individuals, working together in the form of groups, can accomplish well-selected project goals. It also involves the responsibility of influencing the people to positively contribute to reach the goals and objectives of the project.

\subsection{Project Controlling}

It involves the measuring of actual performance, comparison of actual results obtained with expected results and implementation of corrective tasks. Tasks include the controlling of the actions of the people doing the work. Project controlling aspect of any project in fact keeps specialists work together. It also fragments the very complex problems into much simpler tasks and typically assigns them to a different concerned department. Its typical functions include the engineering, finance, marketing and production. Each of these can be further divided into subfunctions. Typical advantages being obtained by it include the centralization of similar usable resources and control there-of, simplified training, no duplication of commonly similar responsibilities on the different projects [8].

Project manager is in fact responsible for managing the controlling of the projects. However, it is essential to firstly analyze the basic reasons of such kind of difficulties before establishing of a new structure. The lack of the proper intercommunication skill is often the one of the major problems held with functional novices which can be consistently handling the routine designs [9]. So far no such kind of handbook yet exists for software projects management and hence the mistakes are often repeated on project after project and y ear after year.

\section{IMPORTANCE OF PROJECT MANAGEMENT}

It has been observed that it is not only the kind of improvement being brought up in project management effectiveness but there are many types of other forces being combined with this aspect to cause use of these emerging methods of project management to explode. Most powerful deriving aspects for projects including the most effective pressures build by the competition to better manage and better reduce the emerging software product life-cycle duration are increasing day by day [10]. Consider the Figure-5 which shows the basic concerns of the project management. Due to all of these reasons the project management has been aggressively implemented in the many different industries [11]. The project management has been intensively used in these industries and also in a large myriad of other ones.

This observed that the project management techniques have a potentially good effect on a firm's bottom line. It has been observed by a set of international studies done in the area of projects development and management that whenever the companies have increased their pre-development emphasis, the predictability of successful new-products commercialization has been increased by an approximately a ratio of 2-to-1 [12]. It has also been observed that whenever the pre-development activities including project definition and project planning are increased, so does the probability of product success.

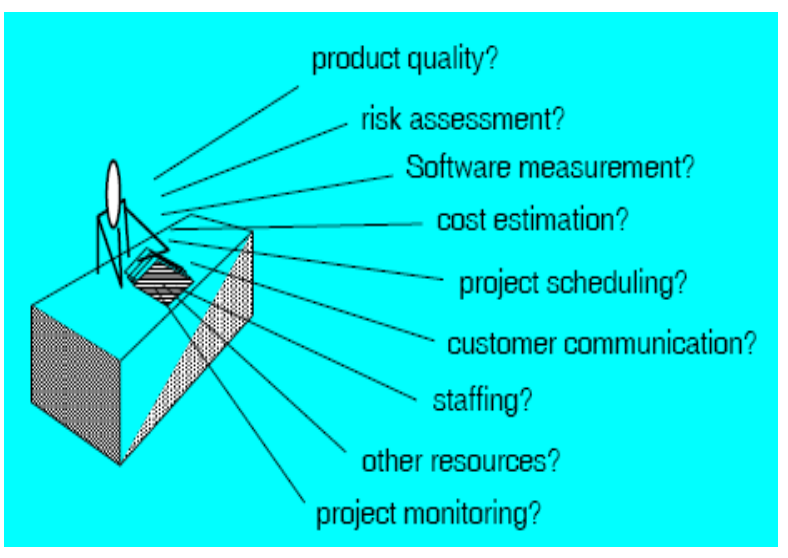

Figure-5: Software Project Management Concerns

There has been a lot of different critical an aly sis and survey that have been conducted to observe the effects of better project management on product and on its quality. After this critical analy sis some of major key factors that have been noticed which are separating the project success from its failure were:

1. Project winners have been found to spend more than almost the twice resources on pre-development activities of the project as compared to the losers.

2. It has been observed that more than $71 \%$ of the new product development was delayed just due to the poor product definitions and poor customer requirements understanding of the project.

3. It has also been observed that the time varying product requirements will induce more specific delays in the product development as compared to any other reason.

It is observed that the project management also has a great affect on the bottom-line of the product development. Since it channels together the specialization into clearly defined internal project cooperation and contribution activities and makes quite clear the ambiguity among the roles and responsibilities in the project, hence it is very suitable in particularly important functional environments. Hence it can be concluded that the development team members may derive motivation values from the overall summary of project planning. It has also been observed that the successful development firms have mastered themselves in the art of melding the main power of human's will and organization. Typically those companies that have the capability to repeat this process again and again over the time are leading in the domain of quality measurements and critical product developments.

\section{TYPICAL PROJECT LIFE CYCLE}

Typically all kind of software projects follow a series of development phases as they progress from the beginning to end. These project development phases are conventionally characterized by the nature of the tasks they are intended to address. Such a kind of set or series of development phases is commonly referred to as the project's life cycle. For project managers it is necessary to understand these phases which definitely help them to organize the project development work. It also helps them to better allocate and control the project resources for the achievement of assigned goals. Conventionally 
project life cycle can be defined in a many ways. In general all kind of development activities of projects can classically be divided into four major phases. These phases include the followings.

\subsection{Project Conceptual}

The basic purpose of the project conceptual phase is to critically determine the development feasibility of the project. In this phase the objectives of the project are analyzed in the context of the business market, development alternatives are abstractly defined and evaluated and a more formal project preliminary cost estimate is determined, more broadly the project development schedule and precise risks are identified [13]. This phase of the project culminates in a broad decision of whether to go ahead with the project or not. It has been observed that a large number of projects do not step bey ond this stage. These projects may be turn out by declaring either to be technically impractical ones, having a huge risk or their estimated costs may outweigh their benefits.

\subsection{Project Planning}

In the project planning phase the main agenda is refine the estimates of the parameters of project performance, project cost and project schedule up to a satisfaction point where the detailed plans for the project execution can systematically be made. Consider the Figure- 6 and Figure-7 which shows the concept of project planning.

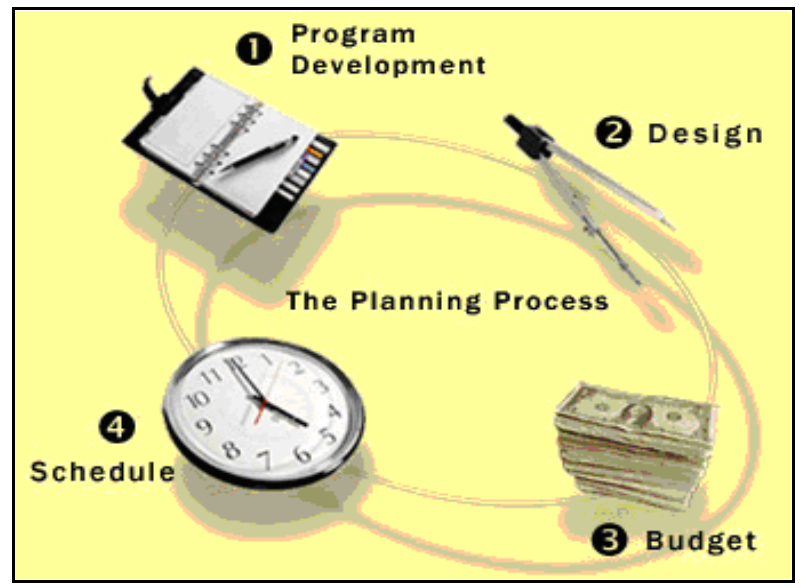

Figure-6: Project Planning Issues

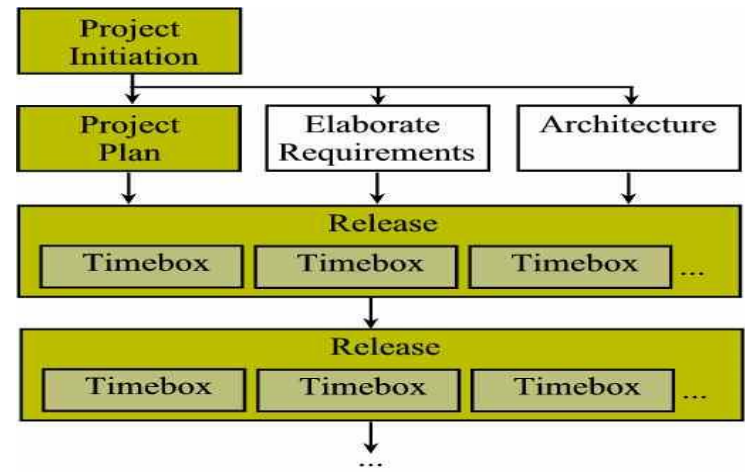

Figure-7: Project Planning Work
In this phase the budgets and schedules for project are developed, the project team is formally defined and a management system for project is established to guide the whole management of the underlying project. Consider the Table-1 which shows the structure of an IEEE based project plane document.

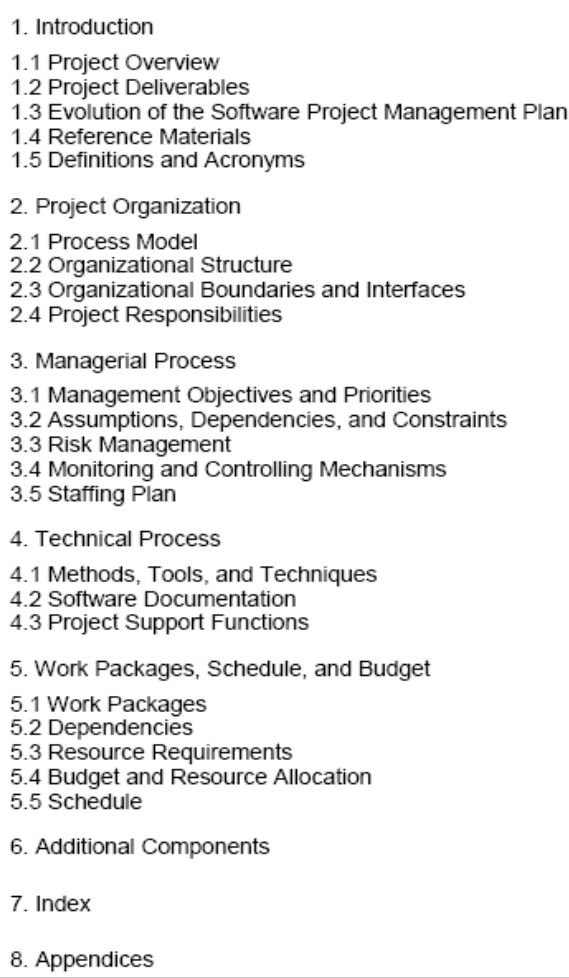

Table-1: Template Document for Project Planning Outline

\section{Project Execution}

The project execution phase basically is concerned with the objective of the carrying out the under laying work as is being defined in the project planning phase. In the phase of project execution, the project manager's responsibility is mainly to manage the project resources which are necessary to accomplish the defined objectives of the project. At this stage the core emphasis of defined responsibilities shifts from project planning to control management. This kind of system implementation has introduced a new set of project management activities and challenges.

\subsection{Project Te rmination}

In the project termination phase the project activities are in fact closed or in other words the set of running activities are phased out. The project closure or termination can be the result of two kinds of events. The project can be triggered out either by premature termination as a result of project failure or by on the other way round it can be done as successful achievement of the defined goals. In both of these situations, the certain types of activities are necessary to positively wrap up against the project. The total number and types of the resources being consumed 
during a typical project may vary from one phase to the next phase.

It has been observed that, normally the resources build up gradually during the preliminary or initial phases of the project. Resource demands and utilization then goes to its peak value in the execution phase of the project. This resource consumption then gradually drops off in the termination phase of the project. In the figure the resource need has been expressed in terms of the total staff-hours over the entire life cycle of the project. It has also been observed that, while the timing of the peak level and the overall level of the resources may vary from one project to another, but generally the basic shape of the shown curve tends to be fairly consistent almost across all of the well defined large-scale projects.

\section{CRITICAL SUCCESS FACTORS FOR PROJECTS}

A lot of work has already been done for benchmarking and standard identifying critical success factors for the project management in using successful projects. Critical success factors are basically those aspects of project development and management which should be followed positively for a project success. Hence in this reference these aspects of project development and management should be given high priority and should be given special and continual looked after from management side so that to ensure project success. Commonly it has been observed that project managers find the critical success factors particularly very useful because most of their working time is consumed in dealing with a set of inter-related such factors. For the whole time of the project management the man gers keep fitting against such factors so that to minimized the project failure probability [14]. Due to this kind of alarming situations caused by during the whole activity of the project management rarely have enough spare time to focus on other relevant issues of projects that are less urgent, but still critically important for the success of the running project. The following is a list of the nominated critical success factors that have been observed from the management of a variety of projects and these factors can help to project managers to focus on those areas which can make difference between success and failure in the field of the software development projects.

\subsection{Clearly Defined Project Objectives}

Complete and clear definition of the project objectives, scope, and practical work to be performed is a key success factor.

\subsection{Executive Support}

Senior project management including project executives shows full commitment by providing all of the necessary resources required by the team members.

\subsection{Adequate Project Budget}

It has been observed that a large class of projects suffer and hence fail just at the start because of availability of adequate budgets.

\subsection{Development of Realistic Schedule}

It has also been observed that a large number of projects simply get off down to a very bad start because of the design of overly optimistic schedules which are mostly caused by unrealistic expectations of customers as well as developers. Consider the Figure- 8 which shows the structure of a basic project schedule.

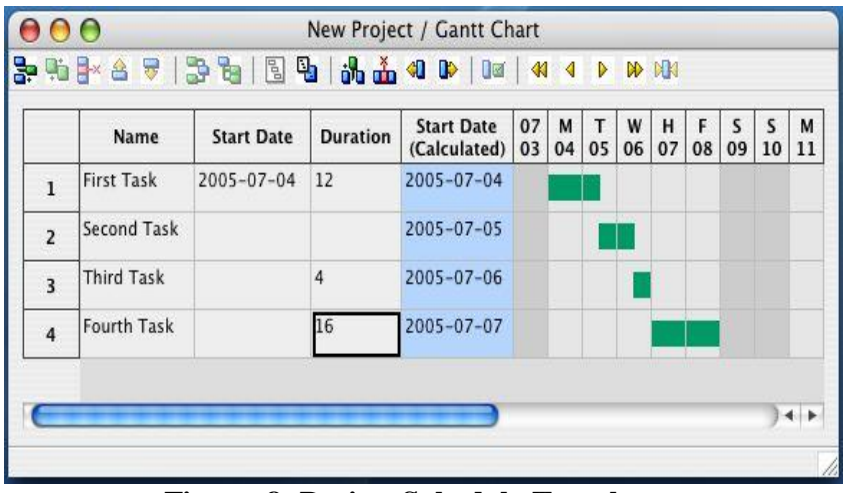

Figure-8: Project $S$ chedule Template

\subsection{Effective Project Leadership}

Project leadership in fact starts with very beginning activity of the selection of the project manager and the key stack holders of his core management team. A quite effective leadership is required to keep the project development as well as management teams being focused and very much motivated throughout the project life.

\subsection{Regular Project Reviews}

It has been observed that the regular and positive project reviews, being held on quite frequently on announced schedules provide the in focus visibility into project progress and its matter of facts like raising problems. Such type of regular project reviews also serve the team as a vital tool for the purpose of sharing vision, motivation for project team members and facilitating the project communications among its executives, man gers and development team members.

\subsection{Project Change Management}

Project change management is a continues process of running a set of activities throughout the project life cycle for critically controlling and monitoring the changes being occurred in the base lined product requirements of the project. The change management is really a challenging aspect for all kinds of complicated major projects in general.

\subsection{Good Communications}

It has been observed that good communications among project team members and all affected parties play a vital role in the success of the project. Historically it can be noticed that a large number of good projects were caused failures because of insufficient communications and miscommunications among the team members of the project.

\subsection{Effective Problem Solving}

The project management comprises of a large number of interrelated development and management activities. The project success is dependant on many different aspects and in general regardless of all of these efforts put for the success of the projects, the problems regarding products, processes, people and technology still do exist in reality. The success of projects is 
greatly dependant on the deployment of an effective mechanism for the anticip ating and problems solving.

The importance of such kind of critical success factors being identified for project management generally varies greatly across different types of running projects. Hence in this reference it is being concluded that primary importance/value of the such kind of generic critical success factors is that they provide a critical in depth analy sis point of departure for project managers to positively develop their own set of action oriented such factors which are appropriate for their specific project requirements.

\subsection{Defining Work B reakdown Structure}

It is observed that the basis for all kind of project planning activities is the Work Breakdown Structure (WBS). WBS in fact decomposes the project into a set of hierarchically well structured, well-defined and well manageable activities. A work breakdown structure can be represented in the form of a multidimensional table or a kind of multi-dimensional chart of entities.

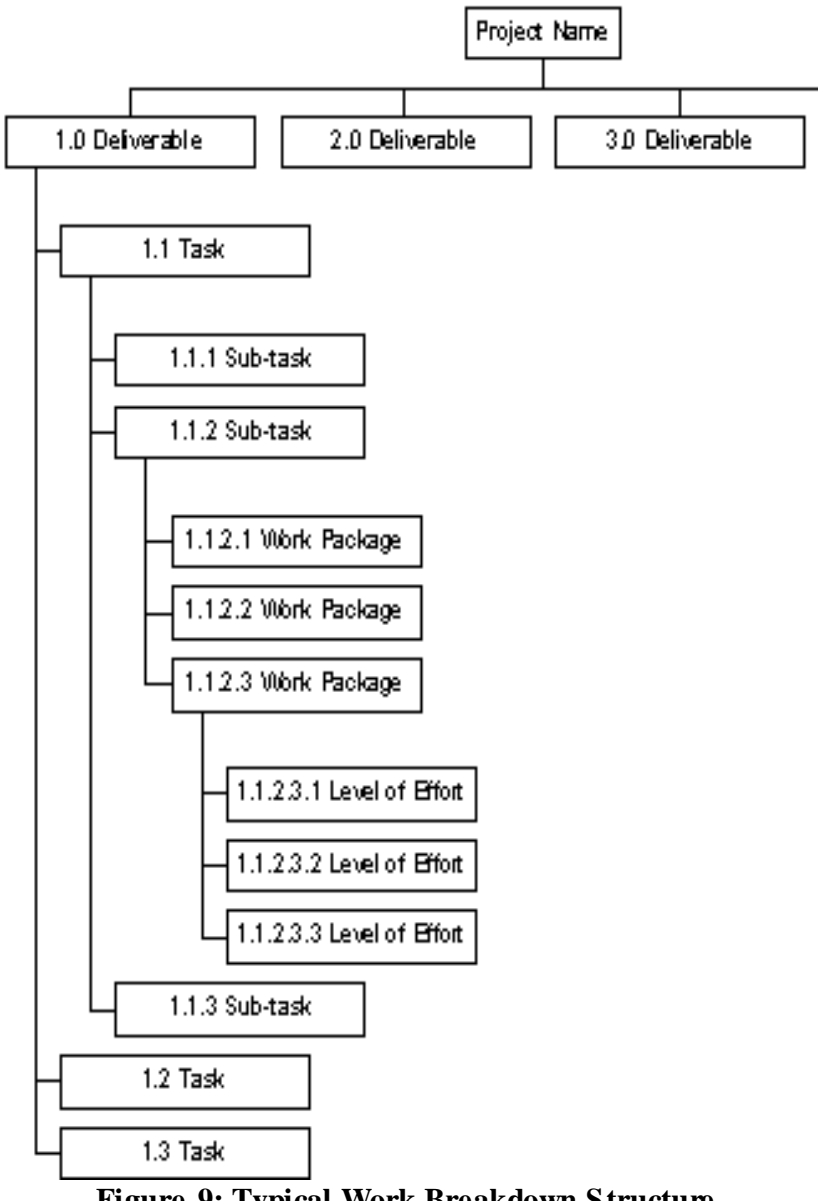

Figure-9: Typical Work Breakdown Structure

The example of the project work breakdown structure is shown in figure-9 which is showing the basic hierarchical relationships among the various activities of the concerned project. The number of levels of detail being displayed in the chart depends mostly on the size of the project as well as on the personal preferences being defined by the project manager. It is quite important that all of the major activities which are defined to be very important and necessary to complete the project should be included in the WBS. Also all of these activities should be assigned to individuals or to specific or ganizations taking part in the development of the project, in an unambiguous manner. The WBS basically provides the fundamental framework of activities for performing the project scheduling, project budgeting and project control. Once the WBS of a project has been defined clearly, the estimating process of the project can now be started.

\section{BENEFITS OF CRITICAL SUCCESS FACTORS}

The major benefits achieved from consideration of the critical success factors are listed below.

- They help the project mangers to think through what is important for project.

- They help the project mangers to maintain the focus on such kind of critical factors.

- They help the project mangers to establish the project priorities.

- They help the project mangers to enhance the inter-related project team's communications and their related shared understandings.

\section{CRITICISM OF CRITICAL SUCCESS FACTORS}

The nominated critical success factors have many benefits but still they are suffering with certain issues. The primary criticisms of critical success factors are that they have been observed to be not the action oriented for most of the time and they also do not provide adequate level guidelines to the project man gers for their management level action. However it has been noticed that critical success factors can be used to develop an appropriate level performance measures. These performance measures can then become most powerful tools for managing under laying projects. In order to reach at these performance measures the following steps might be considered while doing the project management:

- To identify clearly and completely the project goals and objectives

- To define and prioritize the critical success factors

- To develop a set of an appropriate level measures

- To implement the systems for ongoing continuous monitoring of these measures

\section{ASPECTS OF MOST EFFECTIVE PROJECT CONTROL}

Following is a list of those attributes which have been considered as the most important deriving parameters for achieving the more effective project control and management. These attributes will help to the executive management or project managers to make their projects successful.

- In order to reduce the overall complexity of the project, it is recommended to break down the overall project into a series of interlinked development and management phases and work breakdown structure (WBS). 
- It is recommended practice that the project members should clearly and completely define the project objectives, obtained or expected results and all of project deliverables.

- It is also recommended to properly define all of the measurable project milestones and quantitative checkpoints.

- It is required that the project manager should obtain full commitment from all of project team members and management staff.

- It should be made possible for different teams to work together very positively and also the outputs so obtained should be compatible.

- A very effective project tracking should be maintained so that to track the development progress.

- It should be ensured that the measurability of progress parameters is maintained up to the requirements.

- It is recommended to hold the regular project reviews of its goals, its plans and active progress etc.

- Ensure the effective communication among the different working groups of the project including its development teams as well as its management teams.

- A more effective and strong project leadership is the most important factor which leads to the success of the project.

- It is suggested to minimize the project threats by positively managing the conflicts, power distribution issues, avoidance of surprises, unrealistic user demands and foster mutual trust.

- It is suggested to design and maintain an appropriate personnel appraisal and referenced reward system.

- It is required to maintain the continuous involvement of senior project management, endorsement and positive support.

- It is required that the project manager himself should be very much enthusiastic about the success of the project.

- Also it is recommended to note all kinds of the issues and problems that have been experienced in the project database and use it as a reference for future work.

- It has been observed that the successful project management requires a very proper project plan, team commitment, sufficient funds and required resources.

\section{EXISTING B EST PRACTICES OF PROJECT MANAGEMENT}

It is confirmatory that it is not possible to standardize the every practice of software development, but still many of these practices have proven to be good candidate in a large variety of multi-dimensional projects. Most of such kind of well known practices actually come from experience. Hence it would be extremely beneficial for every kind of project that the concerned project manager and its team members of the project development are very much knowledgeable of as many of such kind practices as possible.

The following examples illustrate the idea of using such practices in software project management:

- All deliverables of the product should be very much clearly defined in the early stages of the project.

- This type of communication between the team members of the project is mostly done electronically. However a fraction of time overlap in working hours is definitely desirable. In this way in fact the observation tells us that the establishing the availability standards mostly facilitates the electronic communication in software development being done by the distributed teams of the projects.

- It has been observed that the productivity of a newly established development team must be calibrated in some pilot project. A small pilot project mostly gives the possibility of gaining a rough estimated model of performance for every team member and also for the team as a whole before the start of the real work on a big application.

\section{RESEARCH AREAS IN PROJECT MANAGEMENT}

Since last few decades the project management and its effects on the development of commercial as well as non-commercial products have been studied critically. There have been many types of causes found to be responsible for the failure of a large number of mega projects. In this reference the conclusions and observations made in by the analysts in the domain of project management have been summarized as under, so that to point out the different dimensions of the active issues that can be positively addressed by researchers.

\subsection{Business Benefits of Investing in Project Management}

By looking at the benefits being derived from the mega projects, it has been pointed out by many researchers that there is a need of doing an active research work on the issue getting benefits from the business by investing on the project management [20]. On this issue a huge deficiency of active research by considering the current practices of modern software development industries.

\subsection{Benchmarking Results}

Over the years different aspects of business projects and deriving project management have been addressed. A lot of specs have been collected but yet there is a need of standardizing the benchmarks and applying them on different categories of business projects. Hence in general the benchmarking results so far have not been addressed at the level being required. The studies have been done in this area but yet there is a deficiency which should be covered.

\subsection{New Product Development and Project Management}

The main role of the project management as a dominating paradigm in the field of the new product development has been vital. It is indeed a critical need that it should be addressed in depth and at an appropriate level. New product line is one of the core areas of the industrial zone and by taking an interest in it might raise the productivity of the firms. In this era of fast development, it is the primary requirement of the development of new products that the products should be emergent with an enough level of reliability and fault tolerance.

\subsection{Engineering Management}

Among the new emerging domain of the management, the most prominent one is the domain of engineering management. The domain of engineering management in general has not been well-covered for analysis and research. The guidance provided 
by the project management can be used to make a quite significant contribution for the improvement and deep understanding of this area of knowled ge.

\subsection{Strategy Management in Projects}

Strategy management has been marked as one of the most important areas of attention in field of projects management. There is a wide spectrum of research opportunities in this area as it has been noticed that there has been virtually nothing published on this topic.

\subsection{Value Management}

Among the many aspects of the project management the value management is one of the most important areas which are still in darkness and not much research contributions has been done for it. The value management and value engineering both have significant amount of potential to gain higher business benefits but none of these areas have been actively addressed by the researchers. Also it has been noticed that neither of them has been formally well practiced outside construction.

\subsection{Risk Management}

There has been a lot of work being done in the area of risk management but still it has a lot of potential dimensions and issues which can be addressed further to improve the software development and effective project management. Still there is a significant deficiency in the area of the public's perceptions of risks and risk management.

\subsection{Concurre nt Engineering}

The area of concurrent engineering is developing much faster than ever before. Much of what has been published on concurrent en gineering is still not enough to support the modern requirements. The topic still tends more to be worked out. It has been notified that there has been a short fall in the area of theoretical understanding of core issues of concurrent engineering. Also almost a fraction of work has been done on the development of the supporting tools and technologies for the successfully working on the concurrent en gineering. It is also an important aspect of the concurrent engineering that it should be analyzed for further business and more profit margins.

\subsection{Project Control Manage ment}

The traditional area of project control management is suffering from the emergence of the modern theories and practices to cater the stat-of-art technological projects. Much research work has yet been done but still this topic has a lot of potential for exploring the new dimensions of improvements.

\subsection{Requirements Management}

The area of software requirements management and en gineering has been pointed out as one of the most critical areas of software project development and management. But still much work is required to be done on this topic. The requirements gathering and analysis is still suffering the lack of modern theories and practices. Requirement engineering has already been support with many of the most emerging techniques for gathering and analy sis of the emerging requirements of modern applications.

\subsection{System Engineering and Design Management}

The management practices for system engineering requires further improvements so that to manage the modern highly complex software developments. The lots of issues are here in existence which requires much more efficient work to support the emerging demands of the modern projects. As far as the complexity of the development is concerned the area of systems engineering is considered as one of the most complex areas of science and technology in which a lot of research issues are still buried. Many of old theories have been revolved already to support the existing computing environments but still a lot of more charm is there for project managers and analysts.

The area of design management is now lacking the potential theories and modern practices to fulfill the emerging requirements of the complex system designs. A lot of work is to be required to do on this issues which has not been addressed critically in past. Design management is in fact one of the most thrilling candidate for putting an attentive research eye so that to support the emerging demand of the technology.

\subsection{Marketing and Project Management Relationship}

It has been observed that there is a lot of space for emerging research on the issue of defining the core relation between product marketing and project management. The intent of project management can be critically addressed for defining the inter relationship in since of profit and margins with emerging marketing trend. Lot of new revolutions are required for addressing more critically so that to accomplish the best revenue structures for much better business stability. This dimension of project management has really an immense amount of potential for doing active research work.

\subsection{Private Finance Management}

Private finance has already been well practiced and covered by the researchers but the major areas of conflict and improvement is still creating prominent variations in project management in the domain of construction Along with these mentioned areas the domains of information technology and aerospace are also much more affected.

\subsection{Organization and People Issues}

There is a lot of potential space which can be utilized for further research in the domain of organizational issues and people issues. Like organizational learning is one of many examples where there is lack of genuine new theoretical foundation required to explore. The issues related to people are mostly affected by the developing environment and the social and cultural aspects of the organization. Hence these issues would require close attention by the top management for better improving the project development performance.

\subsection{Project Management Competency Development}

In the domain of project management competency development there are some very important topics which can be further addressed for improvement. These areas include the knowledge 
elements and the modern issues of certification, the relationship with knowledge management and organizational learning. Currently they have been rightly addressed and will further continue to be a most prominent and major area of research enquiry. This area is also linking to business benefit and to career development.

\section{CONCLUSION}

Project management in general has become one of the most important work dimensions of industry. The better project management can save an immense amount of revenue along with the better quality control and optimized development schedules. There have been many different aspects of project development and management that have been classified as the most critical aspects of the development process. The historical benchmarks and the current project management practices have demonstrated that the proper consideration of these critical aspects of project management can lead the industry to a road of guaranteed success and hence can facilitate the society for much better future.

\section{REFERENCES}

[1] Kloppenborg TJ, Opfer WA. Forty years of project management research: Trends, interpretations, and predictions. In: PMI Research Conference. PMI, 2000. p. 41-59.

[2] Crawford L. Global body of project management knowledge and standards. In: Pinto J, Morris G, editors. The Wiley guide to managing projects. New York: Wiley; 2004. p. 1150-96.

[3] Crawford LH. Project management standards: The Value of Standards (DBA thesis) Henley-on-Thames: Henley Management College/Brunel University, 2001.

[4] PMI. A guide to the project management body of knowledge. Pennsylvania, USA: PMI; 2000.

[5] Cicmil, S., Cooke Davies, T., Crawford, L., and Richardson, K. (2009b) Exploring the Complexity of Projects: Implications of Complexity Theory for Project Management Practice Newtown Square, PA: PMI
[6] Crawford L, England, D. Mapping the links between project management and systems. In: Proceedings of IRNOP, vol. 6, Turku, Finland, 2004.

[7] Clegg, S. and Courpasson, D.(2004) 'Political Hybrids, Tocquevillean views on Project Organizations', Journal of Management Studies 41 (4): 525-547

[8] Whitten, N. (2000). How Technical Must a Project Manager Be? Newton Square, PA: Project Management Institute, Inc.

[9] Cicmil, S., Hodgson, D., Lind gren, M. and Packendorff, J. (2009) 'Project management behind the facade.' ephemera: theory and politics in organization, 9(2) pp. 78-92.

[10] Green, S. D. (2006) 'The management of projects in the construction industry: context, discourse and self-identity', in in Hodgson D.and Cicmil S. (eds.) Making Projects Critical, London: Palgrave

[11] Hodgson, D. (2005), 'Putting on a Professional Performance': Performativity, Subversion and Project Management, Organization, 12 (1), 51-68

[12] Lindgren, M. and Packendorff, J. (2009) 'Project leadership revisited: Towards distributed leadership perspectives in project research'. International Journal of Project Organisation and Management, 1 (3) pp. 285-308.

[13] Cicmil, S. and Gaggiotti, H. (2009) 'Who cares about project deadlines? A processual-relational perspective on problems with information sharing in project environments', International Journal of Knowled ge

[14] Hodgson, D. and Cicmil, S. (2007) 'The Politics of Standards in Modern Management: Making 'the Project' a Reality', Journal of Management Studies 44 (3), pp.431450

[15] White D, Fortune J. Current practice in project management - an empirical study. Int $\mathbf{J}$ Project Manage 2002;20(1):1-11. 